\title{
Negotiating lay and professional roles in the care of children with complex health care needs
}

\author{
Susan Kirk MSc BNurs RGN RM RHV DN Cert \\ Research Fellow, National Primary Care Research and Development Centre, University of Manchester, Manchester, UK
}

Submitted for publication 4 September 2000

Accepted for publication 1 February 2001

\author{
Correspondence: \\ Susan Kirk, \\ National Primary Care Research and \\ Development Centre, \\ University of Manchester, \\ The Williamson Building, \\ Oxford Road, \\ Manchester M13 9PL, \\ UK. \\ E-mail:sue.kirk@man.ac.uk
}

KIRK S. (2001) Journal of Advanced Nursing 34(5), 593-602

Negotiating lay and professional roles in the care of children with complex health care needs

Background. Children with complex health care needs are now being cared for at home as a result of medical advances and government policies emphasizing community-based care. The parents of these children are involved in providing care of a highly technical and intensive nature that in the past would have been the domain of professionals (particularly nurses).

Aims of the paper. To assess how the transfer of responsibility from professionals to parents was negotiated, the tensions and contradictions that can ensue, and the implications for professional nursing roles and relationships with parents.

Design. Using a Grounded Theory methodology, in-depth interviews were conducted with 23 mothers, 10 fathers and 44 professionals to gain insight into the experience of caring for children and supporting families in the community.

Findings. From the parents' perspective, their initial assumption of responsibility for the care of their child was not subject to negotiation with professionals. Prior to discharge, parents' feelings of obligations, their strong desire for their child to come home, and the absence of alternatives to parental care in the community, were the key motivating factors in their acceptance of responsibility for care-giving from professionals. The professionals participating in the study had concerns over whether this group of parents was given a choice in accepting responsibility and the degree of choice they could exercise in the face of professional power. However, it was following the initial discharge, as parents gained experience in caring for their child and in interacting with professionals, that role negotiation appeared to occur. Conclusion. This study supports other research that has found that professionals' expectations of parental involvement in the care of sick children role can act as a barrier to negotiation of roles. In this study, parental choice was also constrained initially by parents' feelings of obligation and by the lack of community services. Nurses are ideally placed to play the central role not only in ensuring that role negotiation and discussion actually occurs in practice, but also by asserting the need for appropriate community support services for families. Being on home territory, and in possession of expertise in care-giving and in managing encounters with professionals, provided parents with a sense of control with which to enter negotiations with professionals. It is important that changes in the balance of power does not lead to the development of parent-professional relationships that are characterized by conflict rather than partnership.

Keywords: parental involvement, children with complex health care needs, role negotiation, nursing roles, community-based care 


\section{Background}

Medical advances have enabled increasing numbers of preterm infants and infants with congenital impairments to survive, and have improved the prognosis for children with cancer and chronic illnesses (Woodroffe et al. 1993, Draper 1995). This has resulted in the emergence of a group of children with continuing health care needs, some of whom remain dependent on the technology that enabled them to survive. Accompanying these medical advances has been a move to care for such children at home rather than in hospital. This has occurred in response to policies emphasizing community care for all people with long-term care needs (Department of Health (DOH) 1989) and for sick children in particular (Department of Health \& Social Security (DHSS) 1976, DOH 1991, 1996). These demographic and policy changes have led to complex nursing care being carried out in the home by parents. This relocation of intensive and complex nursing care from hospital to domiciliary settings transfers care-giving from professionals to lay carers, blurring the boundary between lay and professional care (Kirk \& Glendinning 1998).

There has been a lack of research exploring parents' experiences of caring at home for children with continuing needs for medical technology in the United Kingdom (UK). This exploratory study was commissioned as part of the Department of Health's 'Supporting Parenting' initiative to address this omission. This paper describes how the transfer of responsibility from professionals (particularly nurses) to parents was negotiated, the tensions and contradictions that can ensue and the implications for professional roles and relationships with parents.

\section{Literature review}

Relationships between professionals and the parents

of technology-dependent children

North American studies have discovered that relationships between the parents of technology-dependent children and professionals can be problematic in relation to issues such as parental control, the development of trust in professionals and parental concerns over the competency of communitybased nurses (Young et al. 1988, Aday et al. 1989, Scharer \& Dixon 1989, Diehl et al. 1991, McKeever 1991). Parental expertise may be unacknowledged and parents not involved in decision-making (Diehl et al. 1991). Relationships between mothers and professionals in McKeever's (1991) study were characterized by considerable conflict, with parents receiving contradictory messages in relation to their control over care-giving. Similar power conflicts have been reported between professionals and parents during the hospitalization of chronically ill and disabled children. Parents who were competent and confident in caring at home were expected to relinquish control to professionals, their experience and knowledge was disregarded and their competency questioned (Ferraro \& Longo 1985, Robinson 1985, Burke et al. 1991).

\section{Parental participation in care and role negotiation}

'Participation' is a recurrent theme in the conceptualization of professional nursing practice and in policy documents. In the care of hospitalized sick children responsibility for caregiving has been transferred particularly dramatically from professionals to the family (Coyne 1996). Parental participation was originally promoted as a means of reducing the adverse effects of hospitalization on sick children and has gradually evolved from parental provision of everyday childcare activities (for example, bathing) to the performance of clinical procedures such as measuring vital signs, administering drugs, caring for central venous lines and giving intravenous antibiotics (Pike 1989, Evans 1994, Casey 1995). While parent's ability to provide clinical care has been demonstrated, the financial, social and personal costs have been hidden (Cleary 1992, Callery 1997). It appears that there is an expectation from hospital staff that parents will be involved in the nursing care of their child (Brown \& Ritchie 1990, Callery \& Smith 1991). However, there is evidence that such assumptions and expectations of parental involvement (or the degree of that involvement) are not discussed with parents (Algren 1985, Dearmun 1992, Darbyshire 1994). It has been reported that parental willingness, readiness and ability to participate has been based on the subjective judgements and intuitive feelings of professionals rather than on assessment and discussion with parents (Darbyshire 1994, Casey 1995). Parents and professionals may therefore not only be unaware of one another's expectations of involvement, but also have different and possibly conflicting perceptions of parental roles (Hayes \& Knox 1984). At present, it is unclear whether role negotiation between professionals and parents actually occurs in practice (Callery \& Smith 1991, Darbyshire 1994). Studies have shown that professionals, particularly nurses, define appropriate roles for parents and that parents are coerced into becoming unwilling participants in their child's care (Brown \& Ritchie 1990, Darbyshire 1994). Negotiation is dependent upon the social environment, in particular the balance of power (Trnobranski 1994) and power is not evenly distributed between parents and professionals in the hospital context (Callery \& Smith 1991). Parents are on unfamiliar territory, coping with the stress of a sick child and dependent 
on others for information. Consequently, professionals are in the position of power to choose whether or not to negotiate roles and care-giving, while parents are in a weak position to take the initiative (Callery \& Smith 1991).

Although there is a large body of literature on parental involvement in the care of sick children it has been researched overwhelmingly within the hospital context. The perceptions and experiences of parents involved in the provision of clinical care, particularly in the home, have not been fully explored and insufficient attention has been paid to the actual process of role negotiation between parents and professionals.

\section{The study}

\section{Methodology and methods}

The aim of the study was to explore parents' experiences of caring for a technology-dependent child and of the professionals supporting them in the community.

The study used a Grounded Theory methodology which is underpinned theoretically by a symbolic interactionalist view of human behaviour (Blumer 1969). Symxbolic interactionalism emphasizes the importance of the subjective meaning that people impute to actions, objects and society. Research methods that allow the researcher to tap into the subjective understanding of those studied are used in order to uncover their perceptions, feelings and the meanings that participants attribute to social situations.

\section{Sampling}

Families were recruited from three childrens' hospitals with the assistance of nurse specialists and hospital consultants. Initially families were purposefully selected (Table 1).

Each family was contacted by hospital staff to provide information and obtain consent to pass on their details to the researcher. Families were then telephoned by the researcher to discuss their participation in the study and to arrange an interview. At the interview families provided the researcher with the names of all the professionals supporting them in the home and purposeful sampling was used initially to select professionals (Table 1). All professionals contacted agreed to participate in the study and Table 2 presents the sample composition.

Subsequent sampling of parents and professionals was determined by the need to add to the understanding of categories emerging from the analysis. Sample size was determined by theoretical saturation, with interviewing continuing until categories were saturated and no new information was being obtained.

Twenty-three mothers and 10 fathers of 24 technologydependent children were interviewed. All the fathers except one were jointly interviewed with the mother. Four of the families were headed by lone mothers. The children were dependent on a range of medical technologies, many on more than one (Table 3). Only one family was from an ethnic minority group. Although ethnic grouping was not a sampling criteria, three families from ethnic minority groups were selected for interviewing. However, only one of these families agreed to participate in the study. Other characteristics are presented in Table 4.

\section{Ethical considerations}

Approval was obtained from local research ethics committees at each study site. Informed consent was obtained from participants and assurances given of confidentiality and anonymity. Participants were informed of their rights to refuse to answer questions and halt their participation in the

Table 2 The sample of professionals $(n=44)$

\begin{tabular}{ll}
\hline Professional & Number \\
\hline Clinical nurse specialists & 7 \\
Community childrens' nurses & 5 \\
Health visitors & 5 \\
District nurses & 4 \\
Home carers & 4 \\
General practitioners & 4 \\
Community-based social workers & 4 \\
Community paediatricians & 3 \\
Hospital social workers & 3 \\
School head teachers/teachers & 2 \\
Health authority purchasers & 3 \\
\hline
\end{tabular}

Table 1 Purposeful sampling criteria

\begin{tabular}{ll}
\hline Sampling of parents & Sampling of professionals \\
\hline $\begin{array}{l}\text { Range of technological dependencies } \\
\text { Range in the lengths of time that children } \\
\text { had been cared for at home }\end{array}$ & $\begin{array}{l}\text { Range of professional groups and organizations } \\
\text { Range in the technologies of the children that } \\
\text { professionals were supporting } \\
\text { Range of home nursing support services } \\
\text { Range in geographical areas } \\
\text { Range in service configurations (areas with and } \\
\text { without Community Children's Nursing teams) }\end{array}$ \\
&
\end{tabular}


Table 3 The technological dependencies of the children in the sample $(n=24)$

\begin{tabular}{lc}
\hline Technological dependence & Number \\
\hline Tracheostomy & 10 \\
Oxygen therapy & 8 \\
Mechanical ventilation & 6 \\
Intravenous drugs & 4 \\
Parenteral nutrition & 2 \\
Peritoneal dialysis & 2 \\
Others (e.g. gastrostomy) & 13 \\
\hline
\end{tabular}

Table 4 Characteristics of the children in the sample $(n=24)$

\begin{tabular}{ll}
\hline Characteristic & Number \\
\hline Gender & \\
Male & 13 \\
Female & 11 \\
Age (year) & \\
$\quad$ Under 5 & 12 \\
$5-11$ & 6 \\
12-18 & 5 \\
Duration of technology-dependence & \\
$\quad$ Since birth & 13 \\
Following birth & 11 \\
Support from home-care team/workers & \\
$\quad$ With support & 8 \\
Without support & 16 \\
\hline
\end{tabular}

study. Time was spent at the end of the interview ensuring the emotional wellbeing of participants and assessing any need for referral to support services.

\section{Data collection}

In-depth interviews lasting between 1 and 3 hours were conducted with parents in the family home and with professionals at their place of work. Broad, open-ended questions were used to elicit information with the researcher probing for further detail. Questions became more focused and specific as analysis progressed and categories emerged. An interview guide was used for the general direction of the interview but participants were encouraged to direct the conversation into areas of importance for them. All interviews apart from two were tape-recorded and transcribed verbatim. Where it was not possible through lack of consent to tape record, notes were taken during the interview.

\section{Data analysis}

Data collection and analysis occurred concurrently with codes and categories being inductively developed from the data. The transcripts were coded line-by-line using the
NUD*IST (Nonnumerical Unstructured Data Indexing Searching Theory Building) computer program (Qualitative Solutions and Research 1997). Analysis involved identifying codes, their properties and dimensions, clustering together the codes to create categories, systematically comparing and contrasting the codes and categories and examining the connections between the categories and subcategories. The constant comparative nature of the analysis characterizes grounded theory (Strauss \& Corbin 1990). Analytical and self-reflective memos were written throughout the coding process. This paper reports the findings of one of the categories that emerged from the analysis ('negotiating roles'). The names reported in the study are pseudonyms.

\section{Ensuring rigor}

Regular meetings were held with two experts in the field of study throughout the fieldwork and analysis. Coding and a number of transcripts were reviewed jointly to enhance theoretical sensitivity, uncover any researcher biases and clarify the interpretation of the data. Such peer debriefing enhances the credibility and dependability of the analysis. An audit trail outlined the research and the decision making processes with the evolution of the coding and analysis being presented in memos and in the ongoing record kept of the developing NUD*IST tree structure. Rival explanations were explored and deviant cases were identified and the reasons for difference examined. The use of theoretical sampling maximized the range of information obtained.

\section{Findings: negotiating parent and professional roles}

The parents in this study had assumed responsibility both for the day-to-day management of their child's condition and for aspects of service organization. They were involved in performing highly technical procedures that would formerly have been considered part of professional practice, particularly nursing practice. Examples of these procedures include, changing tracheostomy tubes, administering intravenous injections and administering parenteral feeding.

\section{Naïve acceptance}

For most parents the context for initial role negotiation between parents and professionals was the hospital, prior to the child's discharge.

Parental obligations and the desire for discharge

Parents could recall little discussion occurring with professionals before their child was discharged about assuming 
responsibility for care-giving. Parents' feelings of obligations and their strong desire to bring their child home were the key motivating factors in their acceptance of responsibility. Parents felt that to care for their child, whatever the circumstances, was part of a parent's natural duty. Caring for the child at home would also reduce the disruption to family life and improve the child's quality of life. However, parents were unable to foresee the reality of caring for a child with such intensive needs in the home.

It's like when you get a new baby, we wanted Oliver home that much that we did it all, you know you do it because you've got to get him home. When we got him home we just couldn't believe it could we? (Mother of Oliver Oakes).

\section{The lack of alternatives to parental care-giving}

Both parents and professionals were aware that for the child to be discharged home, parents would have to undertake responsibility for their care, as formal services were unable to provide the level of care required by those children with continuous needs, for example, a tracheostomy or peritoneal dialysis. The alternatives to parental care-giving was the child's continued hospitalization, or for the child to go into the local authority care. Professionals may be able to perform intermittent procedures required on a weekly or monthly basis. However, in areas without a Community Children's Nursing (CCN) service, parents were reliant on local adult district nursing teams who might be unwilling to perform clinical procedures for children, feeling that it was an inappropriate extension of their role. This could create additional pressures on parents to accept responsibility for clinical procedures.

It was thus evident that for most of the families there was a minimum parental role consistent with home care and the potential for parents and professionals to negotiate roles was limited by the lack of alternatives to parental care-giving.

I don't know how much choice they are given in that decision. I'm not saying the hospital is wrong, I just think sometimes this has got to be done and nobody says, 'Will you do it?' They just sort of say, 'You'll do it, you'll change this filter three times a day' and nobody says 'Can you or will you or do you want to?' But I think people are frightened to ask, do you want to, in case they say 'No' and then what is the alternative? (Community Children's Nurse 02).

Professionals were aware that parents' feelings of obligation led them to accept responsibility and were concerned about parental exploitation.

\section{Professional assumptions and expectations}

Professionals were concerned that parents were not given a choice about assuming responsibility for clinical procedures.
They felt that the philosophy of parent participation in the care of hospitalized children (and professional expectations) led parents to become involved in care-giving prior to discharge. It was then unquestioningly accepted by hospital staff that they would continue to care for their child following discharge home.

I think a lot of things are accepted as the norm...people think can they do it, not do they want to do it, you know. They sort of say, you know, 'Oh she's bright she's able to do it'. But I think nobody asks do they want to do it. And I think some of it is financial, it needs to be done, and I think nobody gives people the right to refuse. Especially with the big children's hospitals, I think mums go in and see other mums doing something and feel pressurized into doing it. And then it becomes too late because once they've started, they've took on one bit, and they've got to take on all the other bits to go with it (Community Children's Nurse 04).

Professionals felt that it could be difficult for parents to counter professional expectations of parental roles in the hospital context because of power asymmetries.

The ward said, 'Do you want to take them home?' so they didn't feel that they could say 'no'. So they did, and it was a very unhappy situation. Whereas if somebody had sort of questioned her and found out what support she had, or you know, it was all put in place...it's still, you know, they think what they want, not what the families want (Community Children's Nurse 03).

There is an immediate pressure on the parent, usually the mum, to undertake something that they really may not be absolutely happy with...but rather than...be seen to be reluctant to take on extra treatment they would agree to something that really they are best placed saying no to really...we've got some families who don't feel that confident with the medical staff and would just go along with it and not be happy (Clinical Nurse Specialist 06).

During hospital re-admissions hospital staff could have expectations that parents would continue to care for their child, demonstrating the strength of the prevalent ideology in hospitals of parental involvement.

I believe in shared care in hospital, but when she goes in I'm still left to do an awful lot of it and that is a bit annoying at times. I mean I'm happy to do it but sometimes I think, 'Well why should I?', She's in hospital because she's ill, I mean I don't feel as though I should have to be there 24 hours a day, but when I'm not there I expect her to be looked after and sometimes it wasn't happening. I mean one night one of the nurses said to me, 'Where's S (husband)?' I said, 'Well he's gone to see his Nan'. 'Oh well we haven't got the time to set up this TPN (total parenteral nutrition) tonight!! We are very busy, I wanted you and $S$ to do it...' they just take advantage of you because they know you can do these things (Mother of Emma Ford). 
Professional expectations and the lack of appropriately skilled professional care were therefore a barrier to role negotiation.

\section{Informed assertiveness}

Following the child's initial discharge the boundary between parental and professional nursing roles was not static. In response to the child's changing needs, care-giving responsibilities continued to be transferred between parents and professionals (particularly nurses) both during re-hospitalizations and in the home.

\section{Appropriate boundaries}

Parents and professionals identified factors that influenced how they drew the boundary between parental and professional roles. As parents gained experience in caring for their child and interacting with professionals they developed clear views on the appropriate roles for them to assume. Incidents were reported where professionals had expected them to extend the boundaries of their role which parents had resisted. This could be in relation to decision-making in relation to the child's illness, the performance of additional clinical procedures or service organization (for example, obtaining referrals to other agencies). However, it was also clear that some parents would have liked to assume more responsibility from professionals. Appropriateness of parental roles was judged by parents in terms of whether or not they felt that it was in their child's or family' best interests. One family decided to assume responsibility for their child's weekly injection to ensure continuity of care and to reduce distress to their child.

We didn't want to bring in another nurse who was a complete stranger because you do not get the same one every time and somebody else is coming in and giving her an injection (Mother of Clare Jackson).

Another mother was negotiating the transfer of responsibility for her child's monthly Portacath flushes from the nurse specialist and had already successfully negotiated taking over responsibility for replacing gastrostomy tubes.

Now I've said to her to save her coming here, 'Why can't I flush it'. But no-one has ever asked that before. No-one has ever asked can they flush their child's Portacath. So they are still thinking about it (Mother of Katherine Lewis).

Professional participants emphasized that the key factor in determining where the boundary was drawn was the individual parent's preferences and willingness to undertake a given procedure rather than the procedure itself. They noted that there could be particular aspects of a child's care that parents felt unable to perform, on a temporary or permanent basis.

I had one mum who's little one was born with cancer, and she had loads of intervention, home IVs (intravenous infusions), well just about you name it, she did it. But the only thing she wouldn't do was pass a naso-gastric feeding tube. So it was just one thing she couldn't do (Community Children's Nurse 03 ).

They don't want to have to flush Portacaths and do things like that. We've got one or two that do, and I've taught them how to do that. But the ones that don't, I don't feel should be pushed. So I always sort, if that's what they want, if they don't want to do it then that's fine (Community Children's Nurse 04).

However, role boundaries were also determined by professionals' assessment of parents' ability to cope with caregiving and the suitability of the home environment for home care.

Professionals emphasized that determining role boundaries was a parent-led process in which it was important to give parents the choice regarding the responsibilities and roles they assumed in the home context.

We never ever sort of say to the mum, 'Oh you must do this'. We sort of hopefully give them the confidence that they'll say, 'Well I wouldn't mind having a go'. Rather than actually putting the onus, 'I'm here to teach you and you must do it', but let them take it in their own stride, I mean some mums never do it because they just cannot face doing it, but others do and they do it very well, and they actually then become the experts (Community Children's Nurse 03).

Many nurses and doctors saw no limitations to how far parental roles could extend in terms of performing clinical procedures, although there could be differences between specialities in terms of the clinical procedures that parents were performing. Nurses were aware that in some cases parents were performing clinical procedures that would be considered extended nursing roles.

The thing about home IVs (intravenous infusions) and flushing ports and stuff is, you know, qualified paediatric nurses go on a specific course, it's an extended role in the hospital and we try and treat it with the same respect for parents really, it is an extended role (Clinical Nurse Specialist 06).

\section{Asserting the boundary}

The knowledge and expertise parents developed in terms of caring for their child and interacting with professionals was used as a basis from which to be assertive when negotiating roles. With experience, parents could assess the likely costs and benefits to themselves and the family of taking on 
additional roles, and develop the confidence to assert the boundary of their role in encounters with professionals.

She had to have her dressings done twice a day, and to do Emma's dressings takes two of you...it's really difficult to do, and they wanted me to take her home and do dressings twice a day as well as all the TPN (total parenteral nutrition) and everything,...I said, 'Well it's too much to expect, I can't do that! That means getting up another hour earlier...'. Now I just refuse, I did find it hard to refuse at first, I'd say, 'All right I'll take her home' and we'd struggle on with these things, but now I say 'No I'm not prepared to do it' because you realize when you get home you are just on your own. You know, if you can't do it hard lines you've got to do it whether you can do it or not (Mother of Emma Ford).

Professionals felt that parents were able to exercise a greater degree of power in the home than the hospital environment. However, many parents found that being assertive in negotiating roles with professionals was not easy, even in the home.

It's knowing when to feel confident enough to say, 'Well no, I don't want to do this' and you don't, and you don't always feel that confident (Mother of Emma Ford).

I've got to be straight forward and say this is my home, and they are coming in to do a job,...it's so hard, very, it's just difficult you don't want to tread on their toes, 'Right do this, do that', you don't want to be bossy (Mother of Sam Green).

Working with this group of parents was different for professionals because parents, rather than professionals, were often the experts in the child's care. Not only did the parents possess an in-depth knowledge of their own child but they also had the formal knowledge gained from the training they that had received. Parents therefore both possessed and used this knowledge to assess and judge professionals' level of expertise.

She done the opposite of everything that had been done and as soon as she went out the door we had to rip it all off and do it again.... I didn't like saying to her 'You are doing that wrong', to tell a nurse you are doing that wrong...she came the next day and she saw that we'd done it again...she took it all off, bathed it and she done it again her way...So in the end we just had say to her, 'I think we'd best look after this' (Mother of Christopher Cooper).

Professionals who acknowledged their limitations promoted trust in the parent-professional relationship. Continuity in parent-professional relationships was also important in developing a relationship where there was mutual recognition of knowledge and expertise.

If new parental roles were required in response to the child's changing needs professionals described a gradual process of the transferral of responsibility, with parents setting the pace and professionals giving them the confidence to accept responsibility. Professionals had rarely experienced parents deciding to transfer responsibility for continuous clinical procedures back to professionals. They had however, experienced the transfer of responsibility in relation to intermittent therapies where there was an appropriately skilled professional to assume these responsibilities. This was often only a temporary arrangement with professionals working with parents for them to resume responsibility.

Sometimes it's been a very basic procedure, that has perhaps come new to them, maybe they've had the child at home a year, two years, and they've had say more surgery, and they've got to do another procedure... and you'll get an SOS saying, 'I'm not prepared to do this on top of everything else...' it's tended to be that if you've just gone in and done the procedure a day or two for them, by the end of the week they've said, 'Well you've no need to come anymore', I'm all right with this now. And, because it hasn't really been the, the actual procedure that they've not felt able to do, it's just generally they haven't felt able to cope with any more. And it's just been one more thing to do in the day, or it's, I don't know how I'm going to fit this in (District Nurse 02).

Some professionals reported that they used care plans and contracts to formalize role boundaries.

We would formulate the care plan with the family and let them agree to it and we have actually started getting parents to sign the care plan with us, so we would say, 'This is what we have written down about your child, these are the bits that you're saying that you're going to do and these are the things that you want us to do' (Community Children's Nurse 01).

To summarize, it appeared that initially parental roles were rarely negotiated but that parents' feelings of obligation, their strong desire for their child to come home and the lack of alternatives to parental care were the key motivating factors in their acceptance of responsibility. The expectations of hospital staff created additional pressures on parents. However, the subsequent boundary between parent and professional roles was not static. Roles could be negotiated and re-negotiated in response to the child's changing needs and parental experiences of care-giving. Over time as parents gained experience in caring for their child and interacting with professionals, they increasingly defined the appropriate level of and acquired the skills and strategies to assert their role and its boundaries. The determinant for parents of the parent-professional role boundary was their assessment of the potential impact on the quality of life of the family. 


\section{Study limitations}

This study was designed as a small in-depth exploratory study and children with a broad range of technology-dependencies were included in the sample. As with all qualitative studies generalizing to the wider population is not appropriate. The study would have been enhanced by the inclusion of more parents from ethnic minority groups to explore their particular experiences, for example, how language barriers influence role negotiation. The findings on initial role negotiation rely on parents' retrospective accounts and the perspectives of community-based nurses. In addition, the experiences and views of the hospital nurses and doctors were unknown.

\section{Conclusion}

For many parents in the study, exercising any degree of choice over the assumption of responsibility for care-giving was constrained by their feelings of parental obligation, by professionals' expectations of parental involvement and by the lack of alternatives to parental care-giving in the community. The context in which parents found themselves at the beginning therefore did not facilitate the choice that is a prerequisite for role negotiation (Trnobranski 1994).

Initially parents were in a powerless position from which to negotiate care-giving roles with professionals. As Callery and Smith (1991) have reported, parents were not only coping with the stress of having a sick child but were also on unfamiliar territory in the hospital environment where they were dependent on professionals for information. In addition, parental feelings of duty and obligation and their strong desire to care for their child at home meant that parents unquestioningly accepted roles to facilitate their child's discharge without being fully aware of the potential longterm implications for themselves and their families.

Professionals in the hospital had expectations of parental involvement in the nursing care of sick children as other studies have discovered (Brown \& Ritchie 1990, Callery \& Smith 1991). It appeared that it was often assumed unquestioningly that parents wished to be involved in the nursing care of their child and to continue this involvement following discharge. As other research has found (Brown \& Ritchie 1990, Darbyshire 1994), appropriate parental roles were defined by professionals in the hospital context. These decisions appeared to be based more on professionals' perceptions of parental coping and competency than on formal assessments and explicit discussions involving both parents and children.

Professional's lack of negotiation and discussion with parents about their desired level of involvement in care-giving has been reported in a number of studies (Algren 1985,
Dearmun 1992, Ireland 1993, Darbyshire 1994), as has evidence that parents and professionals have conflicting perceptions of what might constitute appropriate and acceptable parental roles in the hospital context (Hayes \& Knox 1984). Professional participants in this study feared that the philosophy of parental participation or parental involvement can be disempowering for parents if its wholesale adoption and professional expectations create a barrier to individualized assessment and role negotiation. As Evans (1994) has noted, parents and families have to be assessed as individuals in relation to their desired level of involvement in the nursing care of their child.

Parental ability to negotiate their role was not only constrained by professionals' expectations and the absence of individualized assessment. In this study, the availability of professional support in the community appeared to be an important determinant of parental and professional roles, particularly in relation to specialist nursing skills. The lack of acceptable alternatives to parental care-giving in the community was a barrier to role negotiation for both parents and professionals. In the community, support services for this group of parents can be absent or under-developed as they have often not kept pace with the medical advances that have been occurring in paediatric care in hospital (Kirk 1999). For example, CCN (Children's Community Nursing) services are not universally provided across the UK and services to provide parents with a break from caring are unlikely to be appropriate for children with specialized health care needs. If parents' preferred roles are constrained by the availability of local services to support them in the home then there is a real possibility that parents are being exploited. Therefore, nurses should be asserting the need for appropriate support services for families and working with other organizations in their development. There is a need to recognize that what is being transferred is not just the responsibility for care-giving but also the direct and indirect costs of caring (Cleary 1992, Callery 1997, Kirk \& Glendinning 1998).

This study found that parents were in a more powerful position to negotiate their role and be assertive with professionals once they were at home, on their own territory. They had developed considerable expertise in caring for their child and had become experienced in interacting with professionals. Parents became more proactive in defining the level of responsibility that they were willing to assume and developed the skills to assert the boundaries of their role both in the home but also in the hospital context when their child was readmitted. Gibson (1995) similarly found that once the parents in her study became aware of their capabilities and expertise they were able to adopt a more assertive role with professionals. 
There are implications for nursing practice as nurses could play the central role in instigating and ensuring that role negotiation with parents occurs both in the hospital and home. However, they need to be aware, and guard against, any assumptions and preconceptions they might have not only about parental involvement but also 'normal' parenting responsibilities and obligations. The nature and level of parental involvement should be negotiated and renegotiated with parents individually and the dynamic context for negotiation recognized, as the needs of both the child and the family may change over time. It is important that as parents move to being more assertive, nurses do not adopt the counter-resistant strategies which McKeever's (1991) study uncovered in an attempt to regain control.

In summary, this study has discovered that the transfer of responsibility for nursing care was constructed by parents and the professionals supporting them in the home as being nonnegotiated. This was not only a consequence of the absence of any process of negotiation as other studies have discovered, but occurred also as a result of parental feelings of obligation and the lack of alternatives to parental caring in the community. The development of parental expertise in caring for their child and in interacting with professionals combined with the context of caring moving to the parents' rather than the professionals' territory provided parents with a sense of control with which to enter the negotiating process. Further research is required to investigate parent participation in nursing care, and the negotiation of parent and professional roles from the home rather than the hospital context.

\section{Acknowledgments}

The author would like to thank Peter Callery and Caroline Glendinning for their comments on drafts of this paper. The views expressed in this paper are those of the author and not those of the Department of Health.

\section{References}

Aday L.A., Wegener D.H., Anderson R. \& Aitkin M. (1989) Home care for ventilator assisted children. Health Affairs 8, 137-147.

Algren C. (1985) Role perceptions of mothers who have hospitalised children. Children's Health Care 14, 6-9.

Blumer H. (1969) Symbolic Interactionalism. Prentice Hall, Englewood Cliffs, NJ.

Burke S., Kaufamann E., Costello E. \& Dillon M. (1991) Hazardous secrets and reluctantly taking charge: parenting a child with repeated hospitalisations. Image: Journal of Nursing Scholarship 23, 39-45.

Brown J. \& Ritchie J. (1990) Nurses' perceptions of parents and nurses roles in caring for hospitalised children. Children's Health Care 19, 28-36.
Callery P. (1997) Paying to participate: financial, social and personal costs to parents of involvement in their children's care in hospital. Journal of Advanced Nursing 25, 746-752.

Callery P. \& Smith L. (1991) A study of role negotiation between nurses and the parents of hospitalised children. Journal of Advanced Nursing 16, 772-781.

Casey A. (1995) Partnership nursing: influences on the involvement of informal carers. Journal of Advanced Nursing 22, $1058-1062$.

Cleary J. (1992) Caring for Children in Hospital: Parents and Nurses in Partnership. Scutari Press, Harrow.

Coyne I. (1996) Parent participation: a concept analysis. Journal of Advanced Nursing 23, 733-740.

Darbyshire P. (1994) Living with A Sick Child in Hospital. The Experiences of Parents and Nurses. Chapman \& Hall, London.

Dearmun A. (1992) Perceptions of parental participation. Paediatric Nursing 4, 6-9.

Department of Health (1989) Caring for People: Community Care in the Next Decade and Beyond. HMSO, London.

Department of Health (1991) Welfare of Children and Young People in Hospital. HMSO, London.

Department of Health (1996) Child Health in the Community: A Guide to Good Practice. HMSO, London.

Department of Health and Social Security (1976) Fit for the Future. The Report of the Committee on Child Health Service (Court Report) Cmnd 6684. HMSO, London.

Diehl S., Moffitt K. \& Wade S.M. (1991) Focus group interviews with parents of children with medically complex needs: an intimate look at their perceptions and feelings. Children's Health Care 20, 170-178.

Draper G. (1995) Cancer In The Health of Our Children: Decennial Supplement (Botting B. ed.), Office for Population Censuses and Surveys, London.

Evans M. (1994) An investigation into the feasibility of parental participation in the nursing care of their children. Journal of Advanced Nursing 20, 477-482.

Ferraro A.R. \& Longo D.G. (1985) Nursing care of the family with a chronicaly-ill hospitalised child: an alternative approach. Image: Journal of Nursing Scholarship 17, 77-81.

Gibson C.H. (1995) The process of empowerment in mothers of chronically ill children. Journal of Advanced Nursing 21, 1201-1210.

Hayes V. \& Knox J. (1984) The experience of stress in parents of children hospitalised with long-term disabilities. Journal of Advanced Nursing 9, 333-341.

Ireland L. (1993) The involvement of parents in self-care practices. In Advances in Child Health Nursing (Glasper E.A. \& Tucker A. eds), Scutari Press, Harrow, Middlesex.

Kirk S. (1999) Caring for children with specialised health care needs in the community: the challenges for primary care. Health and Social Care in the Community 7, 350-357.

Kirk S. \& Glendinning C. (1998) Trends in community care and patient participation: implications for the roles of informal carers and community nurses in the United Kingdom. Journal of Advanced Nursing 28, 370-381.

McKeever P. (1991) Mothering chronically-ill technology-dependent children: an analysis using critical theory. PhD Thesis. York University, Toronto, Canada. 
Pike S. (1989) Family participation in the care of central venous lines. Nursing 3, 22-25.

Qualitative Solutions and Research Ltd. (1997) QSR NUD*IST (Version 4) [Windows]. Qualitative Solutions and Research, Melbourne.

Robinson C.E. (1985) Parents of hospitalised chronically-ill children. Competency in question. Nursing Papers 17, 59-68.

Scharer K. \& Dixon D. (1989) Managing chronic illness: parents with a ventilator dependent child. Journal of Pediatric Nursing 4, 236-247.
Strauss A. \& Corbin J. (1990) Basics of Qualitative Research: Grounded Theory Procedures. Sage, Newbury Park.

Trnobranski P.H. (1994) Nurse-patient negotiation: assumption or reality. Journal of Advanced Nursing 19, 733-737.

Woodroffe C., Glickman M., Barker M. \& Power C. (1993) Children, Teenagers and Health: The Key Data. Open University Press, Buckingham.

Young L., Creighton D. \& Sauve R. (1988) The needs of families of infants discharged home with continuous oxygen therapy Journal of Obstetric, Gynaecological and Neonatal Nursing 17, 187-193. 